\title{
Review of design optimization of fluid machinery: applying computational fluid dynamics and numerical optimization
}

\author{
Qasim Ali Chaudhry ${ }^{1,2^{*}}$ and Qasem M. Al-Mdallal ${ }^{2}$
}

*Correspondence:
chqasim@uet.edu.pk
1 Department
of Mathematics, University
of Engineering \& Technology,
Lahore 54890, Pakistan
Full list of author information
is available at the end of the
article

*Correspondence: chqasim@uet.edu.pk of Mathematics, University of Engineering \& Technology, Full list of author information article

\author{
Book details \\ Authors: Kwang-Yong Kim, Abdus Samad, Ernesto Benini \\ Title: Design Optimization of Fluid Machinery: Applying Computational Fluid Dynamics \\ and Numerical Optimization \\ ISBN: 9781119188308 (ePub) \\ Published by: JohnWiley \& Sons Singapore Pte. Ltd; 2019
}

Keywords: Fluid machinery, Design optimization, CFD, Renewable energy, Numerical optimization

\section{Introduction}

Design optimization has always been popular in many different areas of engineering, especially it has been considered an important tool in the fluid machinery area in the last couple of decades with recent developments in computing power. It is because of the advantages of the optimization techniques and their applications, material on optimization of complex problems is available in literature in the form of books, for example a review of a book (Riaz et al. 2016), in civil engineering (Yang et al. 2015) and in optimization of energy (Badruzzaman et al. 2015). Several books have also been authored in the area of design optimization, for example (Andrés-Pérez et al. 2018; Lei et al. 2016; Sobieszczanski-Sobieski et al. 2015), but the literature of design optimization of Fluid machinery is very little, and this book has tried to fill this gap.

This book consists mainly of five chapters, where each chapter extensively provides the graduate students, engineers and scientists with a general understanding of surrogate-based design optimization of fluid machinery using the numerical tools for complex fluid flow problems, and it also provides a basis to introduce applications of various design optimization techniques to different types of fluid machinery.

The first chapter of the book starts with the introduction of the fluid machinery, its characteristics and classification. The authors have very carefully taken care of the basic principles of mathematical modeling (Chaudhry 2016; Dym 2004; HiriartUrruty 2016; Hiriart-Urruty et al. 2016; Meerschaert 2013; Neittaanmaki 2016) while writing this book. The authors further describe the design requirements and the

(c) The Author(s) 2019. This article is distributed under the terms of the Creative Commons Attribution 4.0 International License (http://creativecommons.org/licenses/by/4.0/), which permits unrestricted use, distribution, and reproduction in any medium, provided you give appropriate credit to the original author(s) and the source, provide a link to the Creative Commons license, and indicate if changes were made. 
methodology for the determination of the parameters for the design optimization of the fluid machinery, and then some problems were discussed.

Chapter 2 provides an extensive literature in the area of fluid mechanics and computational fluid dynamics. This chapter is really helpful not only for the students of the specialized area of fluid mechanics abut also provides a basic knowledge for the new entrants of this area to further work on the design optimization of the fluid machinery and other applications.

The third chapter of this book is completely devoted to discuss the optimization methodology. It can be found in the literature that the design optimization method can be classified in two different approaches or methods; one is gradient-based approach and the other one is statistical methods. Since the design problems have normally large number of design variables, where the computing time definitely depends on the number of these variables, therefore in order to avoid the excessive computational cost and resources, gradient-based methods are normally not recommended to be used especially when dealing with a problem with a large number of design variables. Therefore, in this book, surrogate-based optimization methods based on statistical approach have been used in the design optimization of turbomachinery due to their easy implementation and affordable computing time. This chapter discusses in details the surrogate-based optimization methods, their error analysis, sensitivity analysis examples and inverse design optimization.

Fourth chapter discusses in detail the application of design optimization methods in the area of industrial fluid machinery. The authors have taken several examples (real world applications) of 1-D, 2-D and 3-Dimensional geometry. The methods have been very successfully applied on these problems, solved numerically and then the results have been analyzed. The authors have explained the things in step by step manner by also giving the flow diagrams and algorithms.

In the last chapter, the authors have presented the applications and usage of design optimization methods of fluid machinery for renewable energy systems. The authors have especially focused on the modeling of wind turbines and different classifications of turbines.

As overall, the book is nicely written with multiple examples which not only serves the purpose of providing suitable information but also provides an opportunity to learn and practice the topic in detail. Although, the writers have explained the things with suitable examples together with their solutions but it would have been much better if the writers could provide the Matlab codes of at least few examples for the better understanding. It is fully comprehended and is worth to read. This book aims to provide engineers and graduate students in universities and highly recommended for the students of this area.

Acknowledgements

QAC acknowledges the support given by University of Engineering and Technology, Lahore Pakistan. Both authors would like to acknowledge and express their gratitude to the United Arab Emirates University, Al Ain, UAE for providing the financial support with Grant No. 31S363-UPAR (4) 2018.

\section{Authors' contributions}

QAC conceived the idea. Both authors were equally involved in writing and editing this review article. Both authors read and approved the final manuscript. 
Availability of data and materials

Not Applicable

\section{Competing interests}

The authors note that there are no competing interests.

\section{Author details}

${ }_{1}^{1}$ Department of Mathematics, University of Engineering \& Technology, Lahore 54890, Pakistan. ${ }^{2}$ Department of Mathematical Sciences, College of Science, UAE University, Al-Ain 15551, UAE.

Received: 3 July 2019 Accepted: 21 July 2019

Published online: 30 July 2019

\section{References}

Andrés-Pérez E, González LM, Periaux J, Gauger N, Quagliarella D, Giannakoglou K (2018) Evolutionary and deterministic methods for design optimization and control with applications to industrial and societal problems. Springer International Publishing, Basel

Badruzzaman, M., Foundation, W. R., MWH Americas, I., \& Derceto, I. (2015). Optimization of energy and water quality management systems for drinking water utilities: Final project report. California Energy Commission, Energy Research and Development Division

Chaudhry QA (2016) An introduction to agent-based modeling modeling natural, social, and engineered complex systems with NetLogo: a review. Complex Adaptive Systems Modeling 4(1):1-2

Dym C (2004) Principles of mathematical modeling. Academic press, Cambridge

Hiriart-Urruty J-B (2016) Advances in mathematical modeling, optimization and optimal control. Springer, Berlin

Hiriart-Urruty J-B, Korytowski A, Maurer H, Szymkat M (2016) Advances in mathematical modeling, optimization and optimal control, vol 109. Springer, Berlin

Lei G, Zhu J, Guo Y (2016) Multidisciplinary design optimization methods for electrical machines and drive systems. Springer, Berlin

Meerschaert MM (2013) Mathematical modeling. Academic press, Cambridge

Neittaanmaki P (2016) Mathematical modeling and optimization of complex structures, vol 40. Springer, Berlin

Riaz S, Chaudhry QA, Siddiqui S (2016) Mathematical modeling and optimization of complex structures: a review. Springer, Berlin

Sobieszczanski-Sobieski J, Morris A, van Tooren M (2015) Multidisciplinary design optimization supported by knowledge based engineering. Wiley, Hoboken

Yang XS, Bekdaş G, Nigdeli SM (2015) Metaheuristics and optimization in civil engineering. Springer International Publishing, Basel

\section{Publisher's Note}

Springer Nature remains neutral with regard to jurisdictional claims in published maps and institutional affiliations.

\section{Submit your manuscript to a SpringerOpen ${ }^{\odot}$ journal and benefit from:}

Convenient online submission

Rigorous peer review

- Open access: articles freely available online

- High visibility within the field

Retaining the copyright to your article

Submit your next manuscript at $\gg$ springeropen.com 